\title{
A INFLUÊNCIA DO TIPO FONOTÁTICO NA EMERGÊNCIA DAS VIBRANTES DO ESPANHOL SOB UMA VISÃO DO SISTEMA ADAPTATIVO COMPLEXO
}

\author{
THE INFLUENCE OF THE PHONETIC TYPE IN THE \\ EMERGENCE OF THE SPANISH VIBRANTS THROUGH THE \\ COMPLEX ADAPTATIVE SYSTEM VISION
}

\author{
Jose Rodrigues de Mesquita Neto* \\ Antôno Luciano Pontes**
}

\begin{abstract}
Resumo: Visando analisar a emergência das vibrantes na aquisição da interfonologia do espanhol como língua estrangeira de professores brasileiros de espanhol, partimos da seguinte problemática: de que maneira emerge a interfonologia das vibrantes envolvendo o Português Brasileiro e o Espanhol como Língua Estrangeira de professores brasileiros de espanhol? Temos por hipótese básica que a interfonologia das vibrantes de professores brasileiros de espanhol emergem de modo distinto dependendo do tipo fonotático. Baseamo-nos, teoricamente, em autores como Larsen-Freeman (1997) e Beckner et al. (2009) que tratam a língua como Sistema Adaptativo Complexo. Para a realização da pesquisa, utilizamos uma metodologia experimental de corte transversal e tivemos como corpus de análise a gravação de docentes de espanhol da rede estadual e de cursos livres. Os resultados indicaram que existe competição entre os atratores associados às realizações fricativa e vibrante múltipla. Além disso, a variável tipo fonotático é relevante na construção da interfonologia dos róticos.
\end{abstract}

Palavras-chave: Individuo. Vibrantes simples e múltipla. Sistema Adaptativo Complexo.

\begin{abstract}
Through the purpose of analysing the emergency of the vibrants in the cross languague phonology acquisition of Spanish as a foreign language with brazilian teachers, it configures the following problem question: how does the cross language phonology emerge from the vibrants envolving the Brazilian Portuguese and the Spanish as a foreign language with the brazilian teachers of spanish? As a basic hypothesis we find the cross language phonology of the vibrants in brazilians that teach Spanish emerging from the distinct manner dependending on the phonetics type. The subject in hand was based, theoretically, in authors such as Larsen-Freeman (1997) and Beckner et al. (2009) that treat the language as an complex adaptative system. As for the realization of this research, we used na experimental methodology in a transversal cut and we had a corpus to analyse the record of the professions who teach Spanish in the county schools and franchise courses. The results indicated the appearance of competitive attractors associated with the fricative realizations and multiple vibrant. Moreover, the variable phonetic type is relevant to the cross language phonology construction of the rhotics.
\end{abstract}

Keywords: Individual. Simple and multiple vibrants. Complex Adaptative System.

\section{Introdução}

As teorias fonológicas tradicionais depreendem uma representação fonológica única associada à Língua Materna (doravante LM) e desprovida de detalhe fonético. Desse modo, ignorando a influência das diferentes variantes na emergência da Língua Estrangeira (doravante LE) estudada. Assim, implicando a existência de apenas um percurso de construção da interfonologia de falantes brasileiros de Espanhol como

\footnotetext{
* Professor do Departamento de Letras Estrangeiras da Universidade do Estado do Rio Grande do Norte, campus Pau dos Ferros. Mestre em Ciências da Linguagem pelo Programa de Pós-Graduação em Ciências da Linguagem pela UERN, campus Central. Doutorando em Letras pelo PPGL/UERN, campus Pau dos Ferros.rodrigues_mesquita@hotmail.com

${ }^{* *}$ Doutor em Linguística pela UNESP. Docente do Programa de Pós-Graduação em Letras pela Universidade do Estado do Rio Grande do Norte e do Programa de Pós-Graduação de Linguística Aplicada pela Universidade Estadual do Ceará. pontes321 @ hotmail.com
} 
Língua Estrangeira (doravante ELE). No entanto, estudos associados à visão de língua enquanto Sistema Adaptativo Complexo (doravante SAC) apontam a relevância do uso linguístico na construção das representações mentais. Assim, o estudo de variantes é importante na compreensão do percurso de aquisição de uma LE. Portanto, justificamos a relevância dessa pesquisa por nos desprendermos de uma visão processual no percurso de aquisição.

Assim sendo, buscamos observar o comportamento individual de emergência dos róticos por professores potiguares, pois os agentes dos sistemas se relacionam entre si. Desse modo, essa pesquisa tem como objetivo geral analisar a influência do tipo fonotático na emergência das vibrantes na aquisição da interfonologia do espanhol como língua estrangeira de professores brasileiros de espanhol. Trazemos ainda como objetivos específicos: a) Verificar o efeito dos experimentos na construção da interfonologia das vibrantes simples e múltipla; e b) Analisar o comportamento do indivíduo na emergência dos róticos.

Vários são os motivos que justificam a escolha para a pesquisa. Inicialmente, fomos impulsionados pelo fato de existirem poucos trabalhos que envolvem os aspectos fonético-acústicos dos róticos tomando como base o SAC. Além disso, enquanto professores, percebermos a dificuldade eminente na realização da vibrante múltipla pelos alunos e professores da LE. Adicionamos a isso a fala de Fernández (2007) apontando que a vibrante é o som em que nativos e estudantes de espanhol como língua estrangeira têm maior grau de dificuldade. Por fim, acrescentamos a relevância da pesquisa ao ensino de línguas, pois quanto mais se conhece da gramática fonológica da LE estudada, mais chance se terá de realizar o som de forma mais inteligível e compreensível.

Esta pesquisa é de cunho quali-quantitativo e de corte transversal. Temos como sujeitos dez (10) professores de ELE, sendo cinco (5) da rede estadual e cinco (5) de cursos livres. O corpus está composto pela gravação de 770 tolkens.

O artigo está dividido em três partes centrais, salvo a introdução e a conclusão. $\mathrm{Na}$ primeira, expomos as características da língua enquanto Sistema Adaptativo Complexo. Na segunda, explicamos nossa metodologia, mostrando nossos sujeitos e descrevendo nossos experimentos e variáveis. Por fim, apresentamos nossos resultados e discutimos nossa análise.

A seguir, começamos a seção teórica, nela discutiremos os fundamentos de uma perspectiva dinâmica na aquisição de LE defendendo uma visão de língua enquanto SAC. Para isso, os estudos de Larsen-Freeman (1997), Beckner et al. (2009), Barboza (2013) e Leffa (2016) serão mostrados.

\section{Sistema Adaptativo Complexo}

Iniciaremos explicando os termos que compõem essa teoria. Adaptativo se refere a uma característica do sistema, pois ele está sempre se adaptando em função das modificações de seus elementos, tentando buscar pontos de equilíbrio ao longo de sua trajetória. Já o segundo termo, complexo, reconhece que a linguagem é composta por uma série de variáveis inter-relacionadas. Os elementos "interagem não só dentro do sistema, mas também com elementos externos, estabelecendo relações com o mundo e até agindo sobre ele." (LEFFA, 2016, p. 2).

Para Larsen-Freeman (1997), o enorme número de fatores em interação envolvidos no percurso de construção de uma LE, tais como afetivo, aptidão, idade, 
objetivos do aprendiz, entre outros, caracteriza a natureza complexa do ensino e aprendizagem de línguas.

Ademais, Beckner et al. (2009) nos diz que o SAC é um sistema dinâmico, assim, desenvolvendo-se ao longo do tempo. Por seu dinamismo, a língua pode ser vista e estudada como um Sistema Adaptativo Complexo, pois neste sistema, todos os seus componentes se encontram conectados. Essa conexão se dá através de um sistema de rede.

$\mathrm{Na}$ fig. 1 apresentamos um modelo que representa o percurso de aquisição interfonológico, da vibrante múltipla, em posição onset absoluto, através de um sistema de redes.

Figura 1: Organização em redes dos róticos da interlíngua PB-ELE.

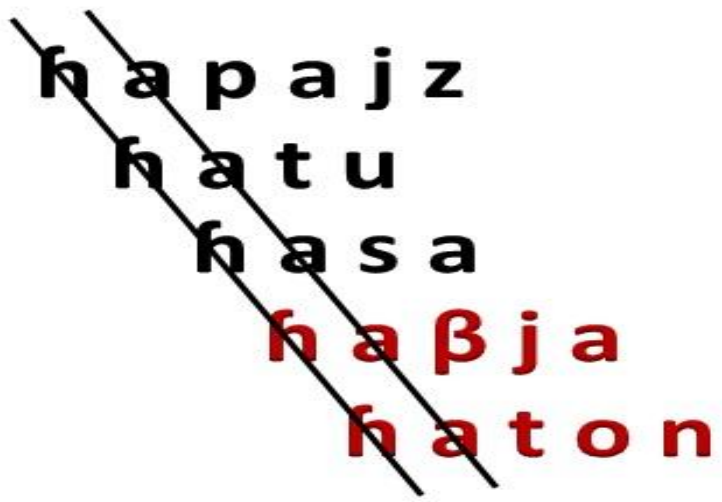

Fonte: Elaboração dos autores.

Enfatizamos, por meio de linhas contínuas, as relações entre as sílabas $\mathbf{h a}^{1}$ do Português Brasileiro (doravante $\mathrm{PB}$ ), em preto, juntamente com algumas palavras do espanhol, em vermelho. A imagem exemplifica a força dos esquemas, cuja produtividade pode ser utilizada em empréstimos e neologismos, por exemplo, principalmente ao aprender uma língua estrangeira como o espanhol com características tão semelhantes, em suas gramáticas fonológicas. A realização padrão do rótico no espanhol, nesse contexto, é a vibrante múltipla r. A fricatização em tal contexto emerge em decorrência da associação entre o PB e o ELE.

Além disso, podemos dizer que o sistema é não linear, pois a alteração inicial que pode acontecer ao se adquirir uma língua é imprevisível. A mudança que a língua pode sofrer está inserida no contexto de sua produção, ou seja, em um meio social, pois a língua não emerge isoladamente. Assim, os SACs são abertos e contextualizados, o que possibilita influenciar e ser influenciado pelo contexto. Assim, Beckner et al (2009, p. 2) nos diz que "o comportamento de um indivíduo é a consequência de fatores em competição, variando de mecanismos perceptuais a motivações sociais ${ }^{2}$. O mesmo autor complementa dizendo que "a estrutura da língua emerge de padrões de experiências interrelacionadas, interação social, e processos cognitivos ${ }^{3}$." Portanto, fica clara a importância da variável indivíduo na análise da aquisição da vibrante.

\footnotetext{
${ }^{1}$ As transcrições serão realizadas em negrito, pois para os modelos fonológicos não estruturais existe uma inter-relação entre fonética e fonologia.

${ }^{2}$ A speaker's behavior is the consequence of competing factors ranging from perceptual mechanics to social motivations.

${ }^{3}$ The structures of language emerge from interrelated patterns of experience, social interaction, and cognitive processes.
} 
A língua como sistema adaptativo complexo apresenta algumas propriedades principais, elencadas por Beckner et al. (2009) e Larsen-Freeman (1997). Nessa abordagem, o SAC é visto como complexo, imprevisível, dinâmico, não linear, sensível às condições iniciais, à auto-organização e à adaptabilidade. Barboza (2013) ainda aponta que os SACs têm como objeto os sistemas caóticos.

O termo caótico foi compreendido no paradigma da complexidade como um comportamento que pode vir a emergir num SAC, não implicando em sua completa desordem. O termo referiu-se à dificuldade de prever acuradamente o comportamento do sistema com o desenrolar da variável tempo. (BARBOZA, 2013, p. 30).

No caso da pesquisa em questão, não há como prever que sons podem emergir da interfonologia rótica do português-espanhol de brasileiros professores de espanhol como LE. Assim, o SAC, por não apresentar linearidade, passa a ilusão de que não é possível extrair nenhuma forma de sistematicidade. No entanto, pensar assim é não conceber a comunicação, pois para que ela exista é necessário um sistema. Em outras palavras, sabemos que há, em tais sistemas, uma tendência à organização, a partir da estabilização em alguns estados mais frequentes do que outros. Bybee (2010, p. 6) nos diz que "a língua é uma das formas mais sistemáticas e complexas do comportamento humano "." No caso dessa teoria, não podemos deixar de lado que o sistema linguístico é mutável e que a variação linguística existe, sendo esta última contínua e resultado direto das características do SAC.

Larsen-Freeman (1997) associa os termos variação e mudança à dinamicidade do uso linguístico. Desse modo, a perspectiva de língua como SAC se diferencia do paradigma linguístico tradicionalista. Além disso, “o paradigma complexo rejeitou o conceito de gramática baseada na aplicação de regras, muito comum nos modelos linguísticos tradicionais." (BARBOZA, 2013, p. 35).

Não é, portanto, possível imaginar a fonética baseada na proposta dos manuais tradicionais, cuja língua é concebida dentro de um sistema linear e estático. Temos que pensá-la considerando todos os elementos que fazem parte do funcionamento da língua e que estão envolvidos no seu uso.

Ao escolher a língua como SAC, aceitamos que há não apenas a complexidade da língua, mas também a do ser humano, com suas interações sociais e experiências. Os SACs são abertos e contextualizados, desse modo não são apenas dependentes do contexto, mas também o influenciam (LARSEN-FREEMAN; CAMERON, 2008).

Portanto, ao considerarmos a língua como SAC, estamos pensando em uma gramática emergente do uso da língua. Na próxima seção, apresentamos a metodologia.

\section{Metodologia}

A presente pesquisa está delimitada como um estudo quali-quantitativo, seguidora de uma metodologia experimental e de corte transversal. Optamos por um estudo de caráter quantitativo, pois optamos por uma análise acústica primordialmente estatística dos dados. Adicionalmente, usaremos parâmetros acústicos para realizar a análise qualitativa, assim, descrevendo os sons que emergem pelos informantes.

${ }^{4}$ Language is one of the most systematic and complex forms of human behavior. 
Para uma melhor explanação da metodologia a dividimos em três partes: Constituição da amostra (3.1), Experimentos (3.2) e Tratamento dos dados (3.3).

\subsection{Constituição da amostra}

Esta pesquisa foi realizada com dez (10) professores de ELE das cidades de Mossoró e Pau dos Ferros, sendo cinco referentes a cursos livres e cinco docentes da rede básica. O corpus de análise foi coletado através da gravação dos mesmos. Utilizamos os seguintes critérios para a seleção dos informantes:

a) falantes potiguares do português brasileiro;

b) não apresentar problemas de audição e/ou fala;

c) não ter períodos de residência fora do Brasil (em países cuja LM seja o espanhol); e

d) não utilizar o espanhol com um cônjuge/parente próximo.

Como tratamos de um trabalho experimental, é necessário apresentarmos as variáveis que levamos em consideração na aplicação dos experimentos. Assim, iniciamos apontando a variável dependente: a emergência dos róticos no ELE. Para avaliar a qualidade da realização, optamos por uma variável binária. Desse modo, verificamos se os informantes realizaram ou não as vibrantes (simples ou múltipla). Caso não, analisamos que realização emergiu.

Apresentada a variável dependente, partimos para as variáveis independentes, estas são: a) tipo fonotático (selecionamos um total de sete que serão apresentados no quadro 1); b) indivíduos; e c) Experimentos.

A seguir apresentamos os experimentos.

\subsection{Experimentos}

Para a coleta dos dados, optamos pela utilização de dois experimentos, sendo um a leitura de frases-veículo (Hable por favor) e o outro uma atividade em que os sujeitos deveriam indicar como chegar a determinados lugares, seguindo um mapa (fig. 2).

Temos consciência que a leitura de frases influencia na realização dos fonemas, constituindo-se uma amostra artificial. No entanto, apoiamo-nos no que Carvalho (2004, p. 16, grifo nosso) diz "ela [leitura de textos] pode ser utilizada para representar o estilo formal da língua, possibilitando, ao mesmo tempo, a qualidade das gravações." Ademais, o experimento 2 é utilizado com a intenção de os informantes utilizarem um falar mais natural e mais próximo da realidade comunicativa. 
Figura 2: Mapa experimento ELE2.

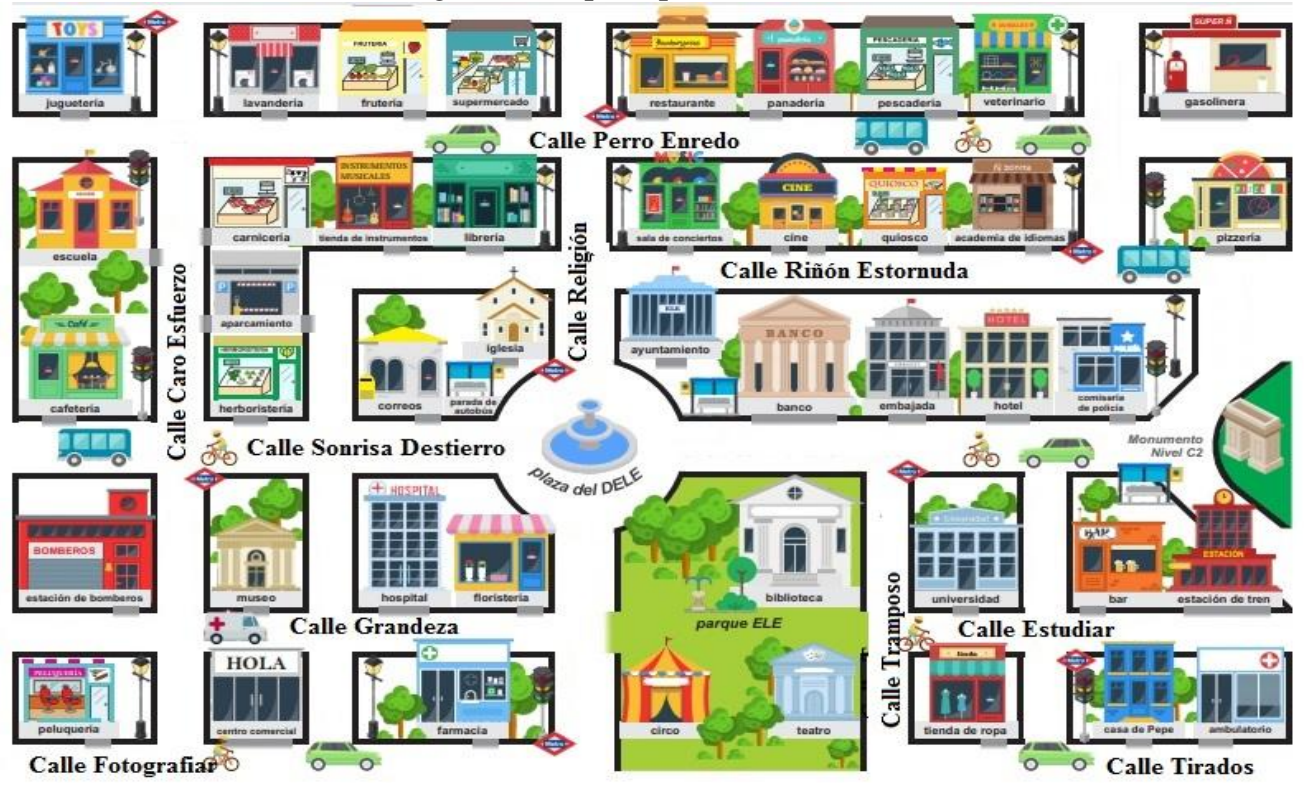

Fonte: profedeele.es (adaptado).

Analisamos 770 tokens, sendo 350 para a leitura das frases-veículo e 420 referentes ao mapa. No primeiro experimento foram trinta e cinco (35) palavras lidas por dez (10) informantes, já no segundo duas palavras foram analisadas em cada contexto fonotático e repetidas três (3) vezes por cada informante. Apresentamos, no quadro 1, as palavras utilizadas em ambos experimentos e seus tipos fonotáticos.

\begin{tabular}{|c|c|c|}
\hline \multicolumn{3}{|c|}{ Quadro 1: Palavras dos experimentos } \\
\hline Tipo fonotático & Experimento I & Esperimento II \\
\hline Onset Inicial & $\begin{array}{c}\text { religión } \\
\text { respuesta } \\
\text { rechazar } \\
\text { riñón } \\
\text { reñir }\end{array}$ & $\begin{array}{l}\text { riñón } \\
\text { religión }\end{array}$ \\
\hline $\mathrm{Rr}$ & $\begin{array}{c}\text { hierro } \\
\text { perro } \\
\text { ferrocarril } \\
\text { destierro } \\
\text { gorra }\end{array}$ & $\begin{array}{l}\text { ferrocarril } \\
\text { destierro }\end{array}$ \\
\hline$\langle\mathrm{n}, \mathrm{l}, \mathrm{s}\rangle+$ Vibrante & $\begin{array}{l}\text { sonrisa } \\
\text { alrededor } \\
\text { honra } \\
\text { enredo } \\
\text { israelita }\end{array}$ & $\begin{array}{l}\text { sonrisa } \\
\text { enredo }\end{array}$ \\
\hline Posição intervocálica & $\begin{array}{l}\text { caro } \\
\text { señorita } \\
\text { mirada } \\
\text { tirados } \\
\text { grosera }\end{array}$ & $\begin{array}{l}\text { caro } \\
\text { tirados }\end{array}$ \\
\hline $\begin{array}{l}\text { Encontro consonantal } \\
\text { tautossilábico }\end{array}$ & $\begin{array}{l}\text { grandeza } \\
\text { mientras } \\
\text { treinta } \\
\text { tramposo }\end{array}$ & $\begin{array}{l}\text { grandeza } \\
\text { tramposo }\end{array}$ \\
\hline
\end{tabular}




\begin{tabular}{|c|c|c|}
\hline & Perogrullo & \\
\hline Coda medial & esfuerzo & esfuerzo \\
& euerta & \\
& horno & \\
& estornuda & \\
& zurdo & estudiar \\
& Estudiar & fotografiar \\
\hline Coda absoluta & mirar & \\
& hablar & \\
& fotografiar & \\
& retroceder & \\
\hline
\end{tabular}

Fonte: Elaboração dos autores.

Expomos, a seguir, como se deu a análise dos dados.

\subsection{Tratamento dos dados}

Os meios físicos para a obtenção das gravações foram constituídos de um gravador digital profissional, do tipo Zoom H6, e um microfone, do tipo Shure SM 58. O microfone utilizado foi um modelo dinâmico unidirecional, cuja frequência de resposta vai dos 50 aos $15.000 \mathrm{~Hz}$.

O estudo foi desenvolvido com a ajuda do programa computacional Praat versão 5.1.43 (BOERSMA; WEENINK, 2012). O mesmo foi utilizado para a observação espectral e oscilográfica dos róticos do ELE.

Os dados analisados foram primordialmente quantitativos. Utilizamos principalmente testes estatísticos de chi-quadrado em sua análise, com o intuito de validar os resultados específicos desta amostra a toda a população de professores brasileiros de ELE. O programa estatístico utilizado na análise foi o SPSS, versão 20.1. Dados qualitativos foram também apresentados, principalmente na discussão de emergências dos róticos do ELE em padrões inesperados.

Na próxima seção, discutimos a análise e os resultados encontrados.

\section{Análise dos dados}

Lembramos que os modelos fonológicos tradicionais desconsideravam o detalhe fonético nas análises interfonológicas. Já os modelos fonológicos que veem a língua como SAC advogam a relevância do detalhe fonético na representação mental da língua materna, o que influencia na realização do ELE de cada indivíduo e contextos fonotáticos de modo distinto. Para o SAC não há falante ideal, pois cada membro de uma comunidade linguística tem experiências linguísticas e extralinguísticas que influenciam nos padrões que emergirão no seu modo de falar (BECKNER et al., 2009).

Nos gráficos, dessa seção, apresentamos e discutimos os dados referentes ao tipo fonotático. Desse modo, espera-se que em posições de onset inicial, $\langle r r>$ e $<n, s, 1>+$ vibrante os róticos estejam associados à realização múltipla. Já nos tipos fonotáticos coda medial, posição intervocálica e encontro tautossilábico espera-se a emergência da vibrante simples. No espanhol apenas essas duas realizações são esperadas.

No graf. 1, observamos a emergência das vibrantes simples e múltipla nos experimentos. $\mathrm{O}$ eixo vertical se refere ao percentual de ocorrências das vibrantes, o $\mathrm{N}$ localizado em cima de cada coluna fez menção ao número de ocorrências real para cada 
grupo (experimentos 1 e 2). As colunas se referem ao número de realizações, sendo as pretas para os casos de vibrantes simples e as cinzas para as vibrantes múltiplas.

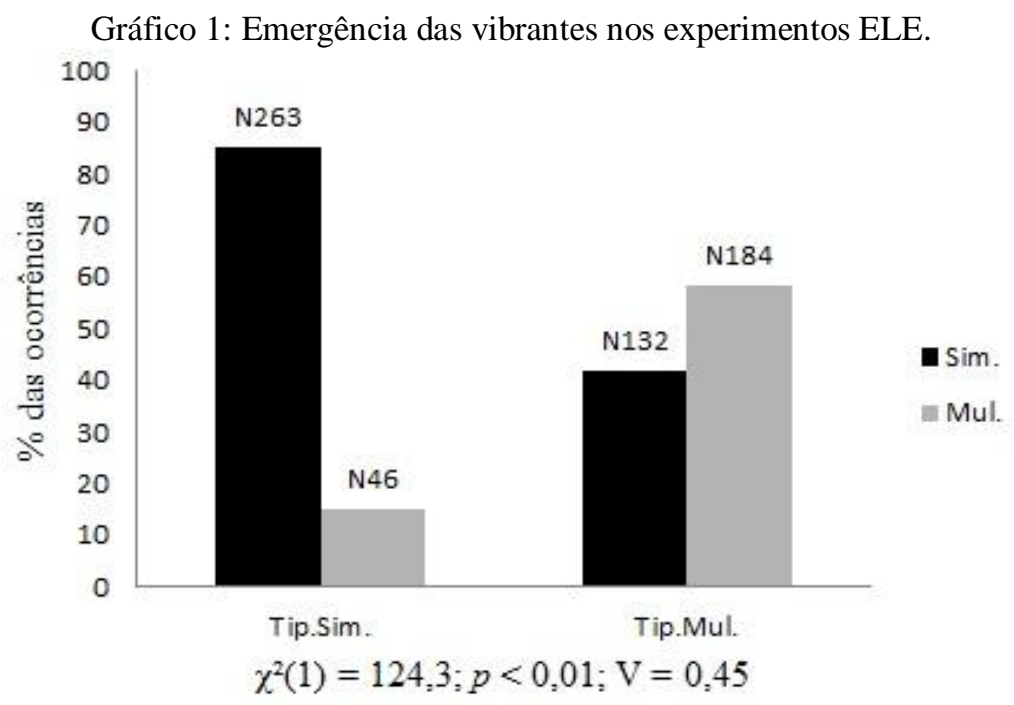

Fonte: Elaboração dos autores.

A análise com relação à variável tipo fonotático apresenta a emergência das vibrantes simples e múltipla de acordo com o esperado na fonologia do espanhol. Os dados indicam diferença entre os grupos, uma vez que existe uma tendência pela realização alvo nos tipos em que a vibrante simples $\mathbf{f}$ deve emergir. Notamos que houve apenas 46 ocorrências diferentes do esperado para esse tipo enquanto nos tipos caracteristicamente associados à vibrante múltipla $\mathbf{r}$ existe uma competição, bem mais forte, entre os atratores. Beckner et al. (2009) associa essa competição entre os fatores como um traço da língua enquanto SAC, pois uma de suas características é a variação. Os novos padrões de uma língua emergem através da competição ou cooperação de seus elementos e/ou atratores.

Ainda sobre o gráf. 1, a análise estatística, realizada através de um teste chiquadrado, indica diferença significativa marcante entre os tipos fonotáticos em questão, indicando que a variável é relevante para a emergência das vibrantes no ELE de aprendizes brasileiros.

Esse resultado conversa com os estudos apontados por Oliveira (2006) em que mostra que o R forte no PB é uma fricativa enquanto que no espanhol é uma vibrante múltipla o que dificulta a aquisição do $\mathbf{r}$ por aprendizes brasileiros de ELE. Além disso, corrobora com Silva (2007) que menciona que essa competição se dá pela falta da vibrante múltipla no falar dos informantes. A autora acredita que a dificuldade de estudantes brasileiros na realização dos róticos recai sobre a vibrante múltipla, visto que a mesma não é utilizada no PB.

Notamos, na fig. 3, que na palavra gorra, realizada pelo informante M2, emerge uma vibrante simples 'gora, quando deveria ser uma múltipla 'gora, assim como nos mostram os estudos de Brisolara e Semino (2014), para esse tipo fonotático. O rótico em questão está marcado por uma única oclusão evidenciando a realização da vibrante simples. Assim, comprovando a competição entre atratores associados à realização do padrão fonotático. 
Figura 3: Espectograma e oscilograma de M2E2Gorra.

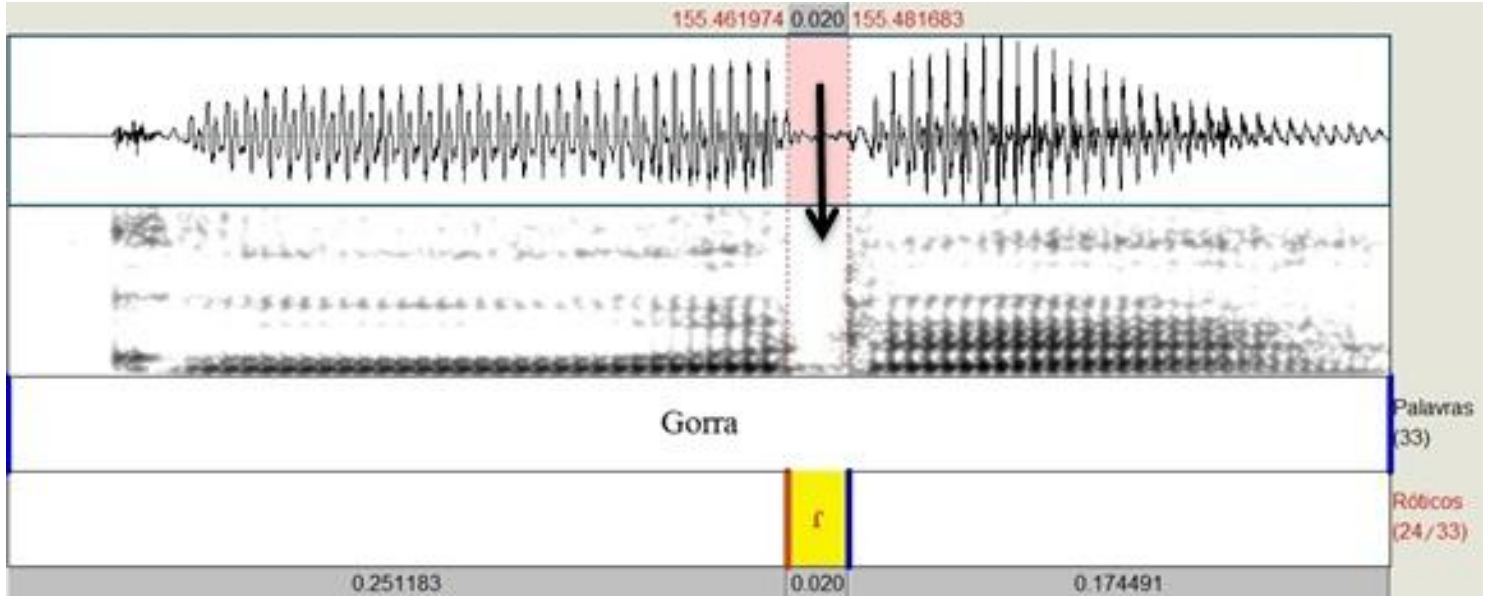

Fonte: Acervo pessoal, extraído das gravações dos áudios no programa Praat.

No gráf. 2, apresentamos a realização dos informantes associada à vibrante simples. No eixo vertical, apresentamos o percentual das ocorrências, o $\mathrm{N}$ representa o número real de ocorrências, sendo as colunas pretas referentes à vibrante simples e as cinzas à vibrante múltipla. Cada conjunto de colunas equivale às realizações em um tipo fonotático específico: coda medial, posição intervocálica e encontro consonantal tautossilábico, respectivamente.

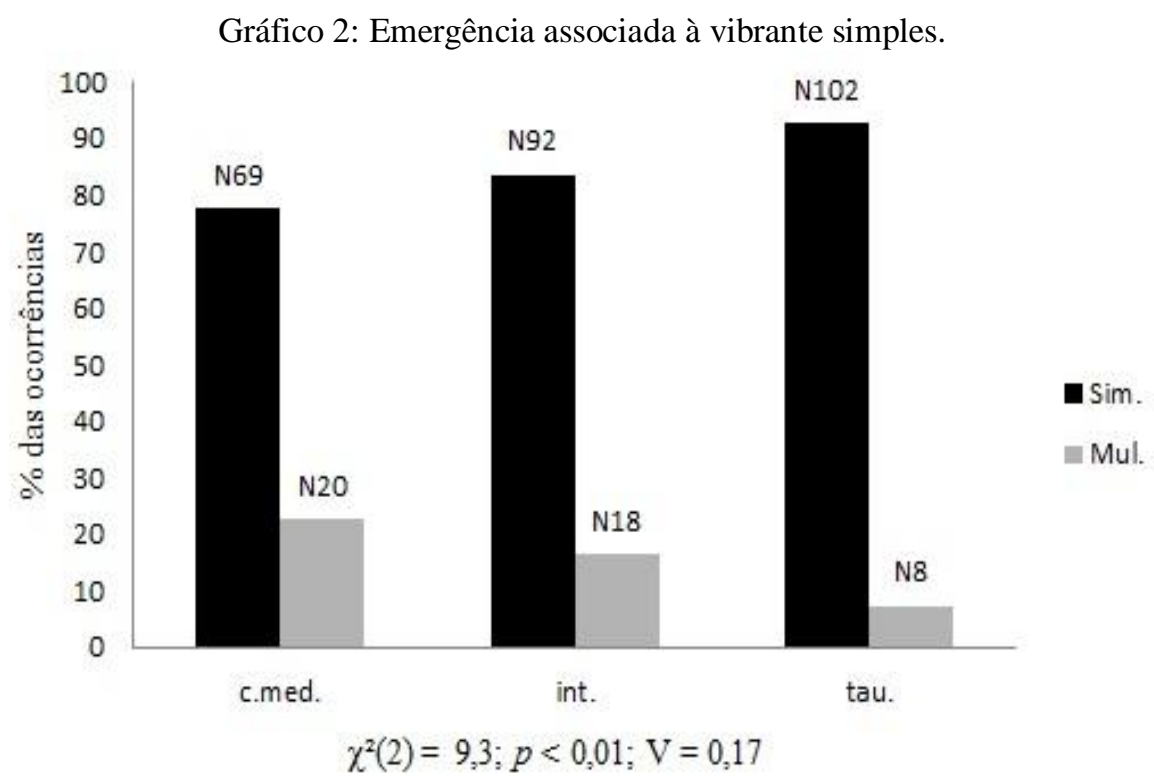

Fonte: Elaboração dos autores.

Nos contextos analisados, em que se esperava a emergência da vibrante simples, a análise estatística aponta para uma diferença significativa entre as variáveis analisadas. Assim, a vibrante simples emerge de modo mais recorrente que a múltipla.

A análise dos dados indica diferença na realização. Nos contextos de coda medial e intervocálica são encontrados valores percentuais semelhantes. Com relação ao número de realizações, há diferença de apenas duas. No entanto, o tipo fonotático 
tautossilábico é o menos susceptível à variação, apesar de a emergência de vibrantes múltiplas, neste contexto, ser inesperada, pois nem no PB nem no espanhol se espera essa realização.

No gráf. 3, apresentamos a variável tipo fonotático associada à vibrante múltipla. Analisamos os seguintes contextos: <rr $>$, onset inicial e $\langle\mathrm{n}, \mathrm{l}, \mathrm{s}\rangle+$ vibrante.

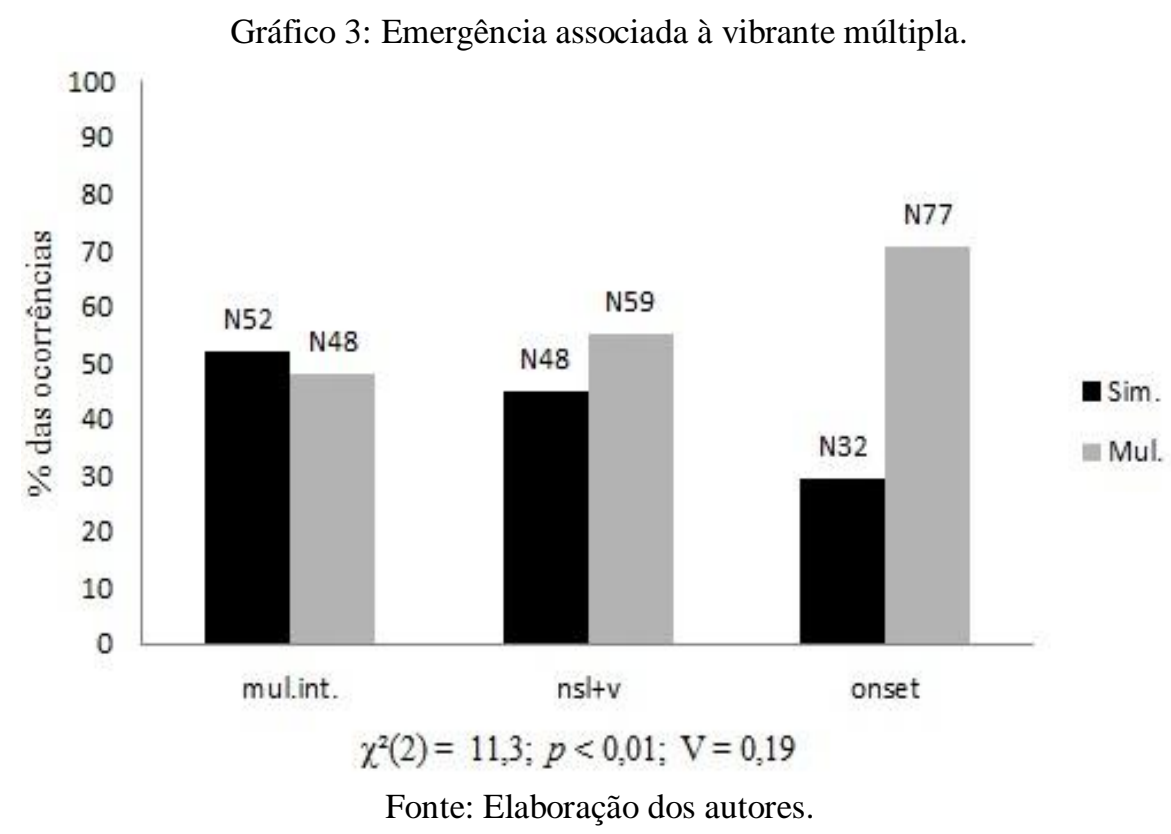

Diferentemente dos tipos fonotáticos relacionados à vibrante simples, constatamos que nos contextos $\langle$ rr $>$ e $<n, 1, s\rangle+$ vibrante há uma forte competição entre os atratores (vibrantes simples e múltipla). Enquanto que em posição onset, o atrator associado à realização da vibrante múltipla é marcadamente mais forte.

Os dados estatísticos demonstram a diferença significativa entre as variáveis. Desse modo, apesar de valores semelhantes em dois conjuntos de dados - contextos intervocálico e $\langle\mathrm{n}, \mathrm{l}, \mathrm{s}\rangle+$ vibrante - indicarem a marcante competição entre as vibrantes simples e a múltipla, mesmo em contexto em que apenas a múltipla é esperada no ELE, o tipo fonotático onset inicial apresenta uma tendência forte o suficiente para garantir a emergência da múltipla nos contextos esperados.

Reforçamos que a força do atrator do PB foi capaz de propiciar a maior emergência da vibrante simples mesmo no contexto da vibrante múltipla intervocálica, em que é marcada na ortografia como <rr>. Assim, demonstrando-se como um atrator profundo. Silva (2007) aponta que nos casos de tipo fonotático vibrante múltipla, o nível de dificuldades dos informantes é maior. Assim, realizando vibrantes simples corroborando nossos achados - ou fricativas.

$\mathrm{Na}$ fig. 4, mostramos a realização de uma vibrante simples quando o esperado seria uma múltipla. Essa competição é causada pelo atrator do PB. 
Figura 4: Espectograma e oscilograma de L3E1Hierro.

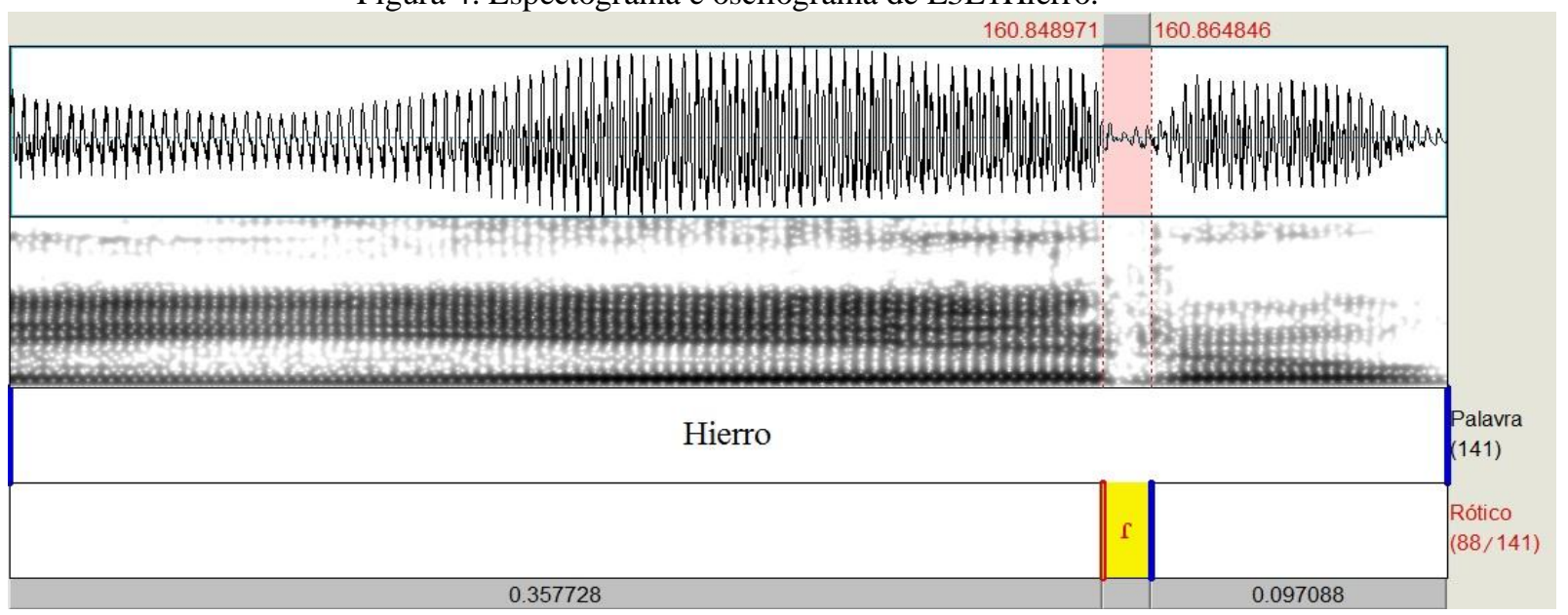

Fonte: Acervo pessoal, extraído das gravações dos áudios no programa Praat.

Os trabalhos de Silva (2007) e Gomes (2013), apesar de não tratarem da língua enquanto SAC, já apontam que a vibrante múltipla está em constante competição com a simples ou recebendo influência do PB. O primeiro apontou que $77 \%$ dos casos em que se esperava vibrante múltipla os informantes realizaram outro som, variando entre tepes (em competição com vibrante múltipla) ou fricativas (influência do PB), já o segundo mostrou que em $75 \%$ dos casos, os informantes realizaram a vibrante múltipla, entretanto, o restante variou entre tepes, sons glotais e velares.

No gráf. 4 expomos a análise da emergência da vibrante simples e múltipla, de acordo com o esperado na fonologia do ELE, com relação à variável tipo fonotático associada à vibrante múltipla excluindo o contexto onset. No gráfico, destacamos as realizações referentes à vibrante em posição intervocálica e $\langle\mathrm{n}, \mathrm{s}, \mathrm{l}\rangle+$ vibrante. As barras pretas se referem à vibrante simples enquanto que as cinzas são referentes à realização da vibrante múltipla. Em cada barra temos o número de realizações.

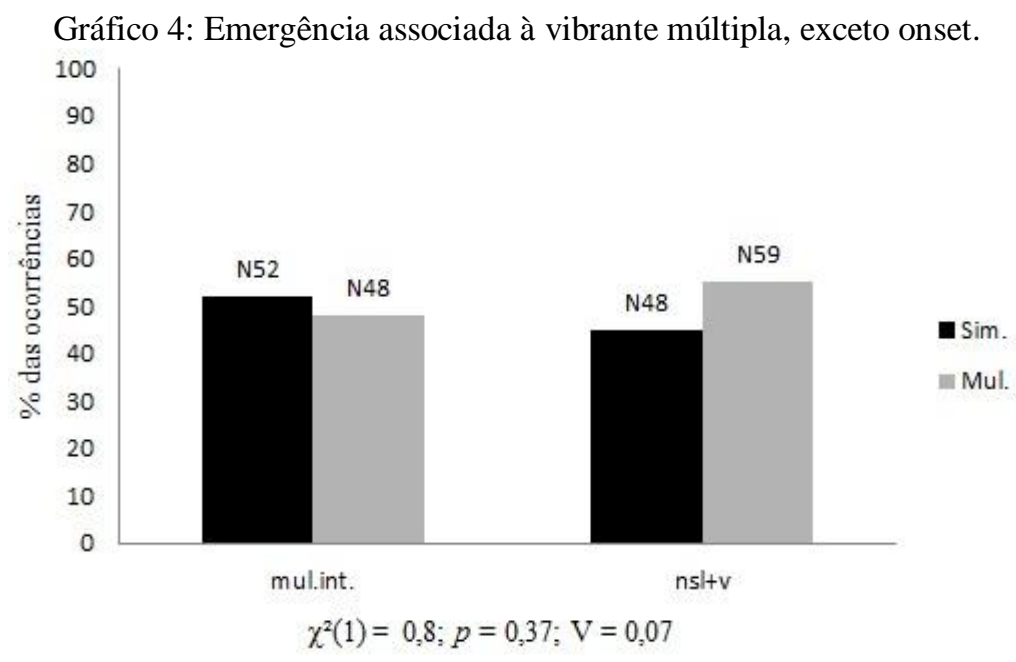

Fonte: Elaboração dos autores.

Notamos, visualmente, que os dados são muito aproximados. A análise estatística confirma diferença não significativa entre as variáveis. Com relação ao 
rótico, em posição intervocálica, observamos um total de 100 ocorrências. Destas, 52 foram vibrantes simples enquanto 48 foram múltiplas. Apesar do número superior para a realização de $\mathbf{r}$, estatisticamente a diferença foi não significativa. Na outra posição analisada $(<\mathrm{n}, 1, \mathrm{~s}\rangle+$ vibrante), observamos que o número de ocorrência da vibrante simples é menor que a múltipla, todavia, a nível estatístico, também há diferença não significativa. Ainda no que concerne a esta posição, salientamos que $\langle\mathrm{n}\rangle+$ vibrante foi o contexto em que os informantes mais se distanciaram da realização esperada, assim como aponta o trabalho de Gomes (2013, p. 77): “[...] esse contexto, segundo o corpus gravado, é o que menos favorece a produção da vibrante".

Conclui-se que o contexto onset é o tipo fonotático mais associado à emergência esperada da múltipla no ELE de aprendizes brasileiros. Outros trabalhos também apontam para esse resultado. Gomes (2013, p. 79) afirma que "a percepção desse segmento, em contexto inicial, parece ser mais fácil para as estudantes perceberem a sua realização, o que poderia facilitar a sua aquisição."

No gráf. 5, analisamos a emergência de fricativas e apagamento não esperadas na fonologia do ELE. Para isso, dividimos o gráfico em três partes: a) realização de fricativas e/ou apagamentos em contextos em que se espera vibrante simples; b) realização de fricativas e/ou apagamentos em contextos em que se espera vibrante múltipla; e c) realização de fricativas e/ou apagamentos em posição de coda absoluta.

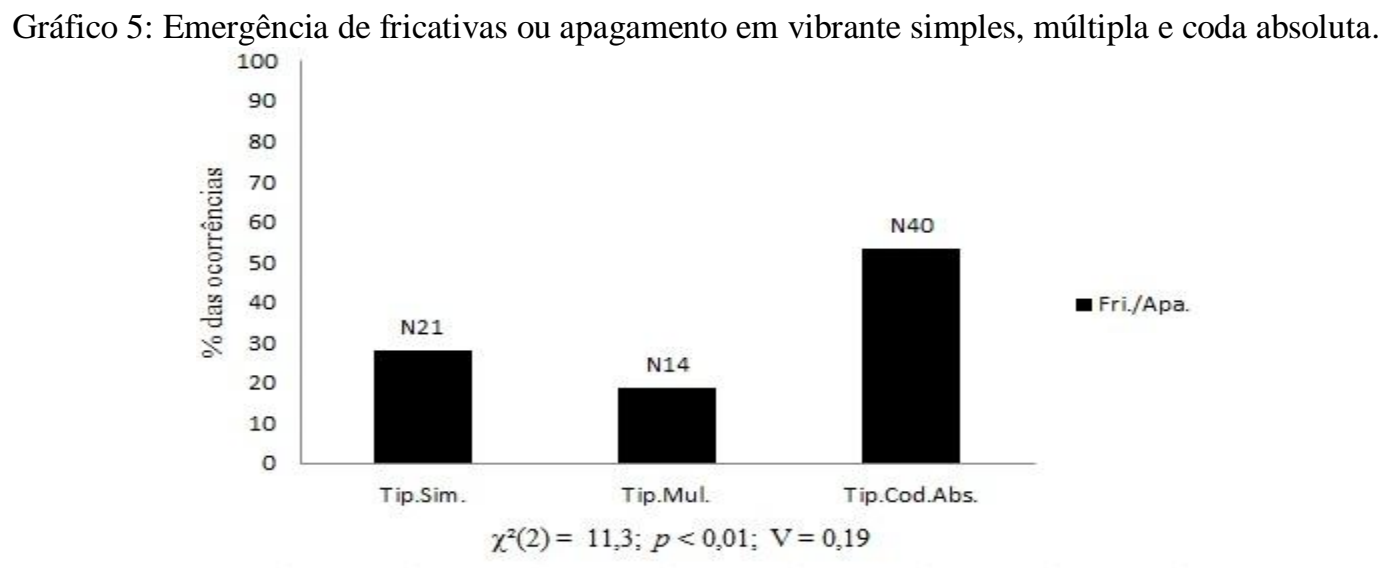

Fonte: Elaboraçãodos autores.

Observamos que atratores do PB estão levando à emergência da interlíngua dos informantes, visto que ocorreram 75 casos que variam entre elisões e fricatizações, sendo 40 em posição de coda absoluta, 21 em tipos fonotáticos que se esperavam vibrante simples e 14 em posições em que o esperado era a vibrante múltipla.

As fricativas e elisões dos róticos são semelhantes nos contextos fonotáticos associados às vibrantes simples e múltipla no ELE, todavia, quando a análise dos dados abrange o tipo coda absoluta, percebemos uma maior emergência deste fenômeno. Os estudos de Gomes (2013) e Milan e Deitos (2016) se preocupam apenas com as realizações referentes aos tipos fonotáticos em que se esperam vibrante múltipla, assim, deixando de lado a posição de coda. No entanto, Silva (2007) e Carvalho (2004) não apontam a coda absoluta como principal contexto de emergência de fricativas ou elisões. Para estas, as fricativas acontecem com mais frequência em onset inicial ou $<$ rr>. Silva (2007, p. 99) ainda afirma que "o contexto que favorece ao uso adequado da vibrante é o final de sílaba". Assim, contrariando nossos achados. 
A análise estatística indica a ocorrência de uma emergência significativamente maior de padrões do PB na posição de coda absoluta. Os dados reforçam a percepção que este tipo é o mais associado à variação em ambos os sistemas, visto que tanto no PB quanto no espanhol, o rótico costuma se neutralizar em posição de coda absoluta.

Enfatizamos que não esperávamos a elisão do rótico em contextos em que o padrão seria uma vibrante simples, assim como observado na fig. 5 .

Figura 5: Espectograma e oscilograma de M2E1Esfuerzo.

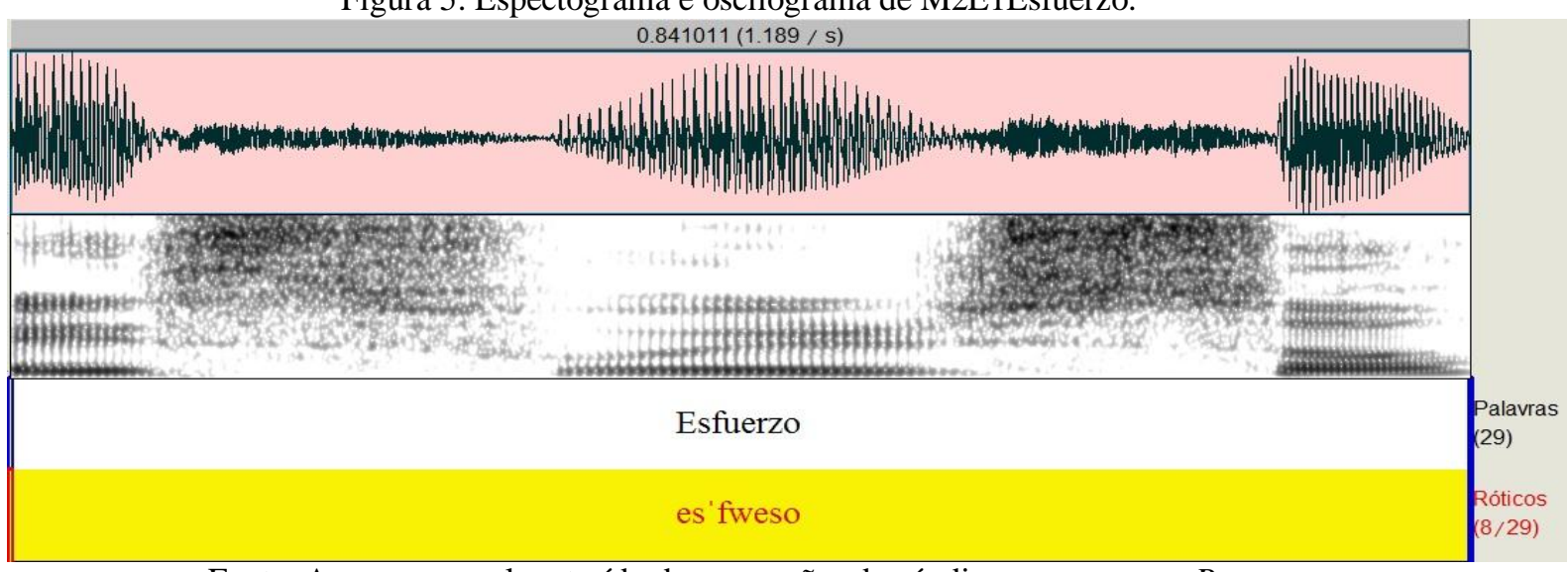

Fonte: Acervo pessoal, extraído das gravações dos áudios no programa Praat.

No espectograma, notamos que a vibrante simples em posição de coda medial é apagada, dando lugar à realização da fricativa da sílaba seguinte. Hipotetizamos que esse fenômeno possa ter ocorrido por se tratar de uma palavra cognata (espanholportuguês), portanto, o informante transferiu características da fala coloquial da sua LM.

Resumindo os achados referentes ao tipo fonotático, apontamos os seguintes: a) existe uma competição mais forte em contextos relacionados à vibrante múltipla; b) nos contextos associados à realização da vibrante simples, o tautossilábico é o menos susceptível a variação; c) no contexto $\langle\mathrm{n}, 1$, s $\rangle$ + vibrante há uma forte competição entre os atratores (vibrantes simples e múltipla), já em posição onset o atrator associado à realização da vibrante múltipla é marcadamente mais forte; d) em posição de coda absoluta há um maior número de apagamento e/ou fricatização; e e) a emergência da vibrante simples é maior mesmo no contexto da vibrante múltipla intervocálica, em que é marcada na ortografia como $<\mathrm{rr}>$.

Na próxima seção, discorreremos sobre as conclusões.

\section{Conclusões}

Este estudo teve por objetivo geral analisar a influência do tipo fonotático na emergência das vibrantes na aquisição da interfonologia do espanhol como língua estrangeira de professores brasileiros de espanhol. Além disso, como objetivos específicos, buscamos: a) Verificar o efeito dos experimentos na construção da interfonologia das vibrantes simples e múltipla; e b) Analisar o comportamento do indivíduo na emergência dos róticos. Desse modo, partimos da seguinte perguntaproblema: de que maneira emerge a interfonologia das vibrantes envolvendo o Português Brasileiro e o Espanhol como Língua Estrangeira de professores brasileiros de espanhol? Tínhamos como hipótese básica que a interfonologia das vibrantes de 
professores brasileiros de espanhol emergem de modo distinto dependendo do tipo fonotático.

No que tange os nossos achados podemos afirmar que a vibrante simples predomina em todos os tipos fonotáticos e que existe uma competição mais forte em contextos relacionados à vibrante múltipla. Nos contextos associados à realização da vibrante simples, a posição tautossilábica é a menos susceptível à variação, já no tipo fonotático $\langle\mathrm{n}, 1, \mathrm{~s}\rangle$ + vibrante há uma forte competição entre os atratores (vibrantes simples e múltipla). Em posição onset, o atrator associado à realização da vibrante múltipla é marcadamente mais forte. Em posição de coda absoluta, há um maior número de apagamento e/ou fricatização. Por fim, a emergência da vibrante simples é maior mesmo no contexto da vibrante múltipla intervocálica, em que é marcada na ortografia como <rr>. Além do apontado, notamos que a variável experimento não influenciou de modo significativo na emergência das vibrantes no ELE de aprendizes brasileiros. O resultado é indicativo que a tendência pela maior dificuldade de emergência da vibrante múltipla é presente nos dois experimentos.

Podemos afirmar que nossa hipótese foi confirmada, pois notoriamente verificamos que os padrões fonológicos se comportam de modo distinto dependendo do contexto fonotático. Desse modo, as conclusões foram pertinentes para uma melhor compreensão do detalhe fonético na construção da fonologia do espanhol como língua estrangeira de professores potiguares.

Apesar de o trabalho focar em professores, consideramos os resultados aqui apresentados relevantes para todos que queiram se aprofundar nos estudos interfonológicos dos róticos PB-ELE, sejam professores, alunos ou pesquisadores. Além disso, o conhecimento aprofundado das regras da gramática fonológica da nossa LM e da LE nos permite menores possibilidades de realizações não padrão da língua estudada.

Em suma, concluímos que o detalhe fonético do PB deve ser observado como fator importante na construção da fonologia do ELE de professores brasileiros. Além disso, esperamos que este trabalho sirva de alicerce para novas pesquisas nesta área.

\section{Referências}

BARBOZA, Clerton Luiz. Efeitos da palatalização das oclusivas alveolares do português brasileiro no percurso de construção da fonologia do inglês língua estrangeira. 2013. 165f. Tese (Doutorado em Linguística) - Curso de Pós-Graduação em Linguística, Universidade Federal do Ceará, Fortaleza, 2013.

BECKNER, et al. Language is a complex adaptive system: position paper. Language Learning, Michigan, v. 51, n. 1, p.1-26, Dec. 2009.

BOERSMA, Paul, WEENIK, David. Praat: doing phonetics by computer. Version 5.1.43. Disponível em: http://www.praat.org. 2012.

BRISOLARA, Luciene; SEMINO, Maria. ¿Cómo pronunciar el español? La enseñanza de la fonética y la fonología para brasileños: Ejercicios prácticos. Campinas: Pontes Editores. 2014.

BYBEE, Joan. Language, usage and cognition. Nova York: Cambridge. 2010. 
CARVALHO, Kelly Cristiane. Descrição fonético-acústica das vibrantes no português e no espanhol. 2004. 213f. Tese (Doutorado em Letras) - Curso de Pós-Graduação em Letras, Universidade Estadual Paulista, Assis, 2004.

GOMES, Aline Silva. A vibrante múltipla espanhola em aprendentes de Espanhol como língua estrangeira na Bahia e em São Paulo: uma abordagem sociolinguística. 2013. 125f. Dissertação (Mestrado em Estudo de Linguagens) - Curso de Pós-Graduação em Estudo de Linguagens, Universidade do Estado da Bahia, Salvador, 2013.

LARSEN-FREEMAN, Diana. Chaos/complexity science and second language acquisition. Applied Linguistics, Oxford, p. 141-165. Jun. 1997.

; CAMERON, Lynne. Complex systems and applied linguistics. Oxford: Oxford University Press, 2008.

LEFFA, Vilson José. ReVEL na Escola: Ensinando a língua como um sistema adaptativo complexo. ReVEL, v. 14, n. 27, 2016 [www.revel.inf.br].

MILAN, P.; DEITOS, G. A vibrante múltipla do espanhol produzida por um falante como L1 e outro falante como L2. Paraná: Revista X, v. 1, p. 47-66, 2016.

OLIVEIRA, Carolina Cardoso. Aquisição das consoantes róticas no português brasileiro e no espanhol: um estudo comparativo. 2006. 175f. Tese (Doutorado em Letras) - Curso de Pós-Graduação em Letras, Pontifícia Católica do Rio Grande do Sul, Porto Alegre, 2006.

SILVA, Kátia Cilene. Ensino-Aprendizagem do espanhol: O uso interlinguístico das vibrantes. 2007. 161f. Dissertação (Mestrado em Linguística) - Curso de PósGraduação em Linguística, Universidade Federal do Ceará, Fortaleza, 2007.

Recebido em 28 de fevereiro de 2019

Aceito em 30 de maio de 2019 